\title{
Evaluation of productive biofilms for continuous lactic acid production
}

\author{
Laure Cuny ${ }^{1} \quad$ Daniel Pfaff $^{1}$ Jonas Luther ${ }^{1} \quad$ Florian Ranzinger $^{1}$ Peter Ödman ${ }^{2}$ \\ Johannes Gescher $^{3} \quad$ Gisela Guthausen $^{1,4}$ Harald Horn $^{1,5} \quad$ Andrea Hille-Reichel $^{1}$
}

${ }^{1}$ Karlsruhe Institute of Technology, EnglerBunte-Institut, Water Chemistry and Water Technology, Karlsruhe, Germany

${ }^{2}$ BASF SE, Ludwigshafen am Rhein, Germany

${ }^{3}$ Department of Applied Biology, Institute for Applied Biology, Karlsruhe Institute of Technology, Karlsruhe, Germany

${ }^{4}$ Karlsruhe Institute of Technology, Mechanical Process Engineering and Mechanics, Karlsruhe, Germany

${ }^{5}$ DVGW Research Laboratories for Water Chemistry and Water Technology, Karlsruhe, Germany

\section{Correspondence}

Andrea Hille-Reichel, Karlsruhe Institute of Technology, Engler-Bunte-Institut, Water Chemistry and Water Technology, 76131 Karlsruhe, Germany.

Email: andrea.hille reichel@kit.edu

\begin{abstract}
In white biotechnology research, the putative superiority of productive biofilms to conventional biotransformation processes based on planktonic cultures has been increasingly discussed in recent years. In the present study, we chose lactic acid production as a model application to evaluate biofilm potential. A pure culture of Lactobacillus bacteria was grown in a tubular biofilm reactor. The biofilm system was cultivated monoseptically in a continuous mode for more than 3 weeks. The higher cell densities that could be obtained in the continuous biofilm system compared with the planktonic culture led to a significantly increased space time yield. The productivity reached $80 \%$ of the maximum value 10 days after start up and no subsequent decline was observed, confirming the suitability of the system for long term fermentation. The analysis of biofilm performance revealed that productivity increases with the flow velocity. This is explained by the reduced retention time of the liquid phase in the reactor, and, thus, a minor $\mathrm{pH}$ drop caused by the released lactic acid. At low flow velocities, the $\mathrm{pH}$ drops to a value where growth and production are significantly inhibited. The biofilm was visualized by magnetic resonance imaging to analyze biofilm thickness. To deepen the understanding of the biofilm system, we used a simple model for cell growth and lactic acid production.
\end{abstract}

\section{KEYWORDS}

lactic acid production, long term fermentation, magnetic resonance imaging, productive biofilm, simulation, tubular biofilm reactor

\section{INTRODUCTION}

For decades, biofilms have been successfully used in bioremediation, mainly in the treatment of wastewater and off gas (Storhas, 2013; Tsoligkas et al., 2011). Recently, the interest in productive biofilms has greatly increased, since the application of biofilm technology has been extended to the production of bulk and fine chemicals (Gross, Schmid, \& Buehler, 2012; Rosche, Li, Hauer, Schmid, \& Buehler, 2009). Biotechnological production processes using bacteria are still mostly limited to batch and fed batch processes, in which planktonic cells grow suspended in a liquid medium and are disposed of at the end of each run (Halan, Buehler, \& Schmid, 2012; Rosche et al., 2009). However, continuous reactor operation is generally expected to be economically advantageous due to the reduction of downtimes for reactor preparation and cleaning (Al Kaidy et al., 2015). The self immobilization and the resulting gentle cell retention of productive biofilm systems allow for a continuous mode of operation with little or no need for active cell separation (Karel, Libicki, \& Robertson, 1985; Posten, 2018). Other well known advantages of biofilms are high resistance to toxic reactants and long term stability as required for continuous processing (Gross, Hauer, Otto, \& Schmid, 2007; Li, Webb, Kjelleberg, \& Rosche, 2006). Additionally, especially in anaerobic fermentation, a higher biomass density is expected in the reactor as compared with planktonic cells, resulting in an increase in volumetric productivity (Brink \& Nicol, 2014; 
Dagher, Ragout, Siñeriz, \& Bruno Bárcena, 2010). However, mass transfer limitations in thicker biofilms, with respect to substrates as well as products, may pose a challenge, making the control of biofilm thickness indispensable (Muffler \& Ulber, 2014). Biomass loss through sloughing events also has a negative impact on biofilm productivity (Brading, Jass, \& Lappin Scott, 1995; Characklis \& Marshall, 1990; Santek, Ivancić, Horvat, Novak, \& Marić, 2006).

To evaluate the potential of biofilm based continuous production of value added compounds, the present study focuses on lactic acid as a model substance. Lactic acid is traditionally used in the food, pharmaceutical and textile industries (Sahm, Antranikian, Stahmann, \& Takors, 2014). Since 2002 the demand has grown by a factor of 10 , mainly due to the synthesis of polylactic acid (PLA), a biodegradable and biocompatible polymer (Ren, 2010). However, the high costs of lactic acid are the reason for its low competitiveness to petroleum derived plastics. The idea to reduce production costs by the use of productive biofilms came up over 20 years ago. So far, approaches are limited to the laboratory scale involving mostly carrier material like plastic composite supports (Demirci \& Pometto, 1995; Ho, Pometto, \& Hinz, 1997; Velázquez, Pometto lii, Ho, \& Demirci, 2001) or polyurethane foam (John, Nampoothiri, \& Pandey, 2007; Rangaswamy \& Ramakrishna, 2008). The use of membranes to increase the area to volume ratio and to facilitate cell attachment has also been investigated (Fan, Ebrahimi, Quitmann, \& Czermak, 2015; Kwon, Yoo, Lee, Chang, \& Chang, 2001). A rather new approach to achieve high productivities for lactic acid is the cultivation of microbial granules. However, the use of a mixed population derived from wastewater treatment makes the product unsuitable for food or cosmetic purposes (Kim et al., 2016).

In this study, we operated a horizontal tubular biofilm reactor (TBR). TBRs have been used for cultivation of different kinds of biofilms for decades (Harald Horn \& Hempel, 1997; H. Horn, Reiff, \& Morgenroth, 2003; Skoneczny \& Tabiś, 2015; Wagner, Manz, Volke, Neu, \& Horn, 2010), however, their application for productive biofilms is still very limited. Brink and Nicol (2014) investigated a heterofermentative Lactobacillus biofilm in a TBR with the focus on the influence of shear on general metabolic changes. The main advantages of TBRs as compared with other reactor types is their simple construction and their easy process set up, as no special carrier material or preliminary growth step is needed. Moreover, the absence of dead zones leads to a more reliable scale up procedure (Santek et al., 2006). The goal of this study was to characterize the performance of a pure culture biofilm of Lactobacillus bacteria for lactic acid production and to evaluate the applicability of a TBR. To deepen the understanding of the biofilm system, a simple model for cell growth and lactic acid production was developed.

\section{MATERIALS AND METHODS}

\subsection{Materials}

All chemicals used in this study were purchased either from Merck KGaA (Darmstadt, Germany) or from Carl Roth GmbH (Karlsruhe, Germany), unless stated otherwise.
The organism cultivated was Lactobacillus delbrueckii, a homofermentative lactic acid bacterium obtained from BASF SE (Ludwigshafen am Rhein, Germany).

\subsection{Growth media and cultivation conditions}

\subsubsection{Preculture}

A $100 \mathrm{ml}$ flask with $45 \mathrm{ml}$ MRS medium (De Man, Rogosa, \& Sharpe, 1960) was inoculated with $5 \mathrm{ml}$ frozen L. delbrueckii cell suspension. The culture was incubated on a magnetic stirrer under anaerobic conditions at $45^{\circ} \mathrm{C}$ for $6 \mathrm{hr}$.

\subsubsection{Batch production culture}

A 2 L stirred tank bioreactor (Biostat ${ }^{\circledR}$ A; Sartorius Stedim Biotech $\mathrm{GmbH}$, Göttingen, Germany) was inoculated with $50 \mathrm{ml}$ preculture (BDM $=1.1 \pm 0.2 \mathrm{~g} / \mathrm{L}$ ), cultivated as described above. The production medium had the following composition: $100 \mathrm{~g} / \mathrm{L}$ glucose, $20 \mathrm{~g} / \mathrm{L}$ yeast extract, $1.0 \mathrm{~g} / \mathrm{L} \mathrm{KH}_{2} \mathrm{PO}_{4}, 0.5 \mathrm{~g} / \mathrm{L} \mathrm{MgSO}_{4} \cdot 7 \mathrm{H}_{2} \mathrm{O}, 100 \mathrm{~g} / \mathrm{L} \mathrm{CaCO}_{3}$ as a buffering agent, $1 \mathrm{ml} / \mathrm{L}$ of both mineral salts and vitamin stock solution. The mineral salts stock solution consisted of: $5.80 \mathrm{~g} / \mathrm{L}$ $\mathrm{ZnSO}_{4} \cdot 7 \mathrm{H}_{2} \mathrm{O}, 5.60 \mathrm{~g} / \mathrm{L} \mathrm{FeSO}_{4} \cdot 7 \mathrm{H}_{2} \mathrm{O}, 1.70 \mathrm{~g} / \mathrm{L} \mathrm{MnSO}_{4} \cdot \mathrm{H}_{2} \mathrm{O}, 2.5 \mathrm{~g} / \mathrm{L}$ $\mathrm{CuSO}_{4} \cdot 5 \mathrm{H}_{2} \mathrm{O}, 2.8 \mathrm{~g} / \mathrm{L} \mathrm{CoSO} \mathrm{C}_{4} \cdot 7 \mathrm{H}_{2} \mathrm{O}$, and $40 \mathrm{~g} / \mathrm{L}$ citric acid monohydrate. The vitamin stock solution contained: $0.05 \mathrm{~g} / \mathrm{L}$ biotin, $1.0 \mathrm{~g} / \mathrm{L}$ Ca pantothenate, $1.0 \mathrm{~g} / \mathrm{L}$ nicotinic acid, $2.0 \mathrm{~g} / \mathrm{L}$ myo inositol, $1.0 \mathrm{~g} / \mathrm{L}$ thiamine $\mathrm{HCl}, 1.0 \mathrm{~g} / \mathrm{L}$ pyridoxine $\mathrm{HCl}, 0.2 \mathrm{~g} / \mathrm{L}$ para aminobenzoic acid, and $0.3 \mathrm{~g} / \mathrm{L}$ riboflavin. The $\mathrm{pH}$ value was adjusted to 6.0 before inoculation and was kept around 5.0 by the buffering agent. The temperature was controlled at $45^{\circ} \mathrm{C}$.

\subsubsection{Biofilm production culture}

The biofilm culture was grown in a horizontal TBR made of glass (ID $=10 \mathrm{~mm}, L=400 \mathrm{~mm}$ ). Right before the inflow as well as right behind the outflow of the TBR, sampling sites were implemented in the system (Figure 1). As medium reservoirs and tempering units, two $2 \mathrm{~L}$ stirred tank bioreactors (Biostat ${ }^{\circledR} \mathrm{A}$; Sartorius Stedim Biotech $\mathrm{GmbH}$, Göttingen, Germany) were installed in line with the TBR. The production medium had the same composition as in the batch culture apart from reducing the glucose concentration and replacing the buffering agent $\mathrm{CaCO}_{3}$ with $0.1 \mathrm{~g} / \mathrm{L} \mathrm{CaCl}_{2} \cdot 2 \mathrm{H}_{2} \mathrm{O}$ as a calcium source. After inoculation of the medium in reservoir 1 , the biofilm was first grown in recycle mode. During this phase, the medium was pumped through the TBR in intermittent operation with 15 min pumping at a flow velocity of $v=1.06 \mathrm{~mm} / \mathrm{s}$ alternating with $60 \mathrm{~min}$ rest. Glucose concentration was kept at approx. $1 \mathrm{~g} / \mathrm{L}$ by regular addition of substrate. The $\mathrm{pH}$ was controlled automatically at 6.0 by $\mathrm{NaOH}$ addition. After a visible biofilm had developed after $48 \mathrm{hr}$, reactor operation was changed to continuous mode for further biofilm growth and lactic acid production. Therefore, reservoir 1 was replaced by reservoir 2 , containing sterile medium with $5 \mathrm{~g} / \mathrm{L}$ glucose and the biofilm was cultivated at a flow velocity of $0.3 \mathrm{~mm} / \mathrm{s}$ without recycling the spent medium back to the reservoir. A bubble trap was 


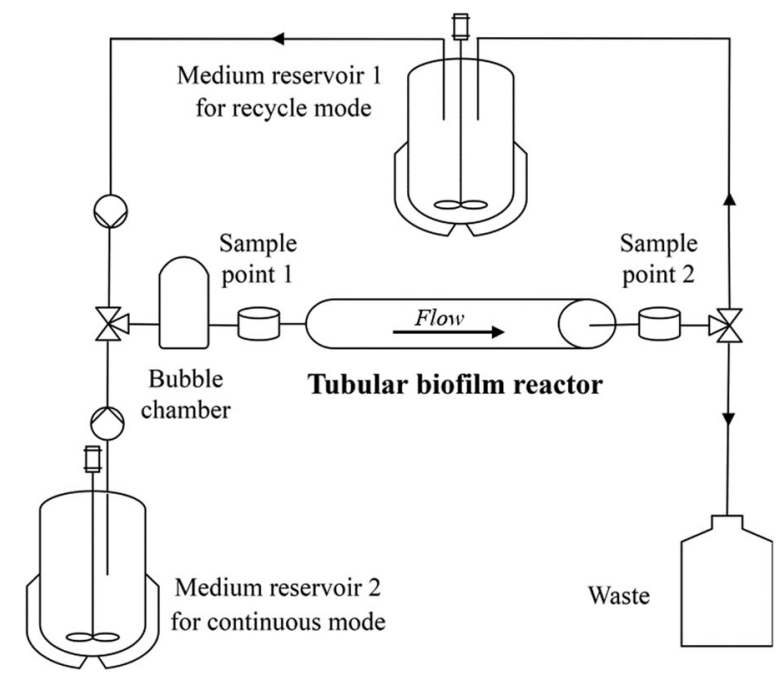

FIGURE 1 Experimental set up for the tubular biofilm reactor (ID = $10 \mathrm{~mm}, L=400 \mathrm{~mm}$ )

used to avoid the introduction of gas into the TBR. To analyze the impact of flow velocity on biofilm productivity, short term experiments at flow velocities of $0.32,1.06$, and $2.12 \mathrm{~mm} / \mathrm{s}$ were conducted almost daily. The experiment was terminated after approx. one month, when nearly constant productivity was achieved.

\subsection{Determination of biofilm biomass}

At the end of the experiment, the biomass growing on the inner walls of the TBR was determined as biomass wet weight (BWW) after drainage at an angle of $45^{\circ}$ for $5 \mathrm{~min}$. For the determination of biomass dry weight (BDW), the biofilm was scraped off the walls completely and the TBR was rinsed with normal saline. The suspension obtained was filtered and the filters $(0.2 \mu \mathrm{m}$, nitrocellulose) were dried for $12 \mathrm{hr}$ at $110^{\circ} \mathrm{C}$ and weighed on a high precision balance. The water content was determined as the ratio of BDW to BWW.

\subsection{Analytical methods}

Planktonic cell growth was determined by measurement of optical density at a wavelength of $600 \mathrm{~nm}\left(\mathrm{OD}_{600}\right.$; UV-Vis Spectrometer, Lambda XLS, Perkin Elmer, Waltham, MA) with cell free supernatant used as blank. Optical densities were related to biomass dry weight (BDW) concentrations by using a calibration curve.

Glucose and lactic acid concentrations were determined using high performance liquid chromatography (Agilent Technologies, Santa Clara, CA) combined with RI and UV detector (210 nm), respectively. Broth samples were centrifuged and the supernatant was diluted for analysis if necessary. An ion exclusion column (Rezex ROA organic acid $\mathrm{H}+(8 \%), 300 \times 7.8 \mathrm{~mm}$; Phenomenex, Torrance, CA) was used at a temperature of $55{ }^{\circ} \mathrm{C}$ with $2.5 \mathrm{mM} \mathrm{H}_{2} \mathrm{SO}_{4}$ as a mobile phase at a flow rate of $0.5 \mathrm{ml} / \mathrm{min}$. The injection volume of the sample was $20 \mu \mathrm{l}$.
Biofilm visualization by magnetic resonance imaging (MRI; Herrling, Guthausen, Wagner, Lackner, \& Horn, 2015; Wagner et al., 2010) and confocal laser scanning microscopy (CLSM; Neu \& Lawrence, 2014; Neu et al., 2010) was performed after the experiment was terminated. To analyze the extent and distribution of biofilm growth over the cross sectional area of the TBR, three coplanar axial slices perpendicular to the horizontal axis of the TBR (position 1: $70 \mathrm{~mm}$; position 2: $200 \mathrm{~mm}$, position 3: $330 \mathrm{~mm}$ ) were measured with MRI. Before imaging, the TBR was drained, re filled with normal saline and vertically positioned at the center of the MRI magnet. MRI was performed on a Bruker Avance 200 SWB spectrometer (Larmor frequency: $200 \mathrm{MHz}$, magnetic flux density: 4.7 T, vertical bore magnet with an ID of $150 \mathrm{~mm}$, inner diameter of the ${ }^{1} \mathrm{H}$ bird cage: $20 \mathrm{~mm}$; Bruker BioSpin $\mathrm{GmbH}$, Rheinstetten, Germany), using a fast low angle shot sequence (Callaghan, 1993; Kimmich, 1997). The field of view was $20 \mathrm{~mm} \times 20 \mathrm{~mm}$, and an in plane spatial resolution of $156 \mu \mathrm{m}$ was used. MRI parameters are provided in Table S1. Data was acquired within ParaVision 6.0.1. (Bruker BioSpin GmbH, Karlsruhe, Germany), and processed in Avizo (FEI Visualization Sciences Group, Merignac, France) and via self written scripts in Matlab (version R2012a; MatlabWorks Inc.; Natick, MA).

An undisturbed sample of biofilm at the inlet of the TBR was visualized on the microscale $(0.08 \mu \mathrm{m} /$ pixel) with CLSM on a Zeiss LSM700 microscope (Carl Zeiss Microlmaging GmbH, Jena, Germany). Nucleic acids and glycoconjugates were stained with SYTO60 (ThermoFisher Scientific Inc., Waltham, MA) and BanLec (Vector Laboratories Inc., Burlingame, CA), respectively, using a FITC and an A633 filter. Microscopy was done with a water immersible lens (magnification $\times 40$, Objective W Plan Apochromat 40×/1.0 DIC, Zeiss, Germany).

\section{SIMULATION OF PRODUCT FORMATION IN THE TBR}

\subsection{Theory}

The biofilm model used to represent the experimental data for cell mass $(X)$, product $\left(c_{P}\right)$ and substrate $\left(c_{S}\right)$ concentrations have been developed based on the widely used equation of Monod (Monod, 1949), that includes a growth associated production. The maximum specific growth rate $\left(\mu_{\max }\right)$ was determined by batch experiments whereas the Monod constant $K_{\mathrm{S}}$ of $0.01 \mathrm{~g}$ glucose/L was adopted from literature (Yabannavar \& Wang, 1991). As the simulation results proved to be insensitive to the precise value of $K_{\mathrm{S}}$ in the range below $1 \mathrm{~g} / \mathrm{L}$ (results not shown) and as the initial substrate concentrations in the experiments were by orders of magnitude higher, an experimental determination of $K_{\mathrm{S}}$ was considered unnecessary. So far, simulations for lactic acid production have only be reported for planktonic cells in the batch mode (Kumar Dutta, Mukherjee, \& Chakraborty, 1996; Kwon et al., 2001; Yeh, Bajpai, \& lannotti, 1991). These simulations include a growth inhibition term taking into account the undissociated product (Kumar Dutta et al., 1996; Yeh 
et al., 1991). As the product concentration in the present study is far below the inhibition concentration, this term can be neglected in the biofilm model. However, in contrast to batch experiments, the $\mathrm{pH}$ is not regulated inside the TBR. As the $\mathrm{pH}$ drop resulting from product formation has also an inhibitory effect on growth and production, a growth inhibition term was included, that depends on the concentration of released protons $\left(c_{H}\right)$ and an inhibition constant $\left(K_{H}\right)$. The prediction of $\mathrm{pH}$ change in the medium as a function of the formed acid was determined experimentally. According to Luedeking Piret (1959), a nongrowth related production term, depending on the actual cell density, was added for the rate of product formation, with a maximum specific production rate $\beta_{\max }$ determined by batch experiments. Biomass detachment was assumed to be a function of the growth velocity of the biofilm $u_{F}$ (Horn \& Hempel, 1997; Wanner \& Reichert, 1996), with the proportionality constant referred to as detachment coefficient $\left(k_{\mathrm{D}}\right)$. Biomass and product yields, $Y_{\mathrm{XS}}$ and $Y_{\mathrm{PS}}$, were determined in batch experiments or in the continuous study, respectively. The processes are summarized in Table 1.

\subsection{Model development}

In this study, we used the AQUASIM 2.1 software (Reichert, 1994) to model the biotransformation of glucose to lactic acid within a productive biofilm. The confined biofilm reactor compartment offered by AQUASIM was used, which consists of a "bulk fluid," a "biofilm solid matrix," and a "biofilm pore water" zone (Wanner \& Morgenroth, 2004). The bulk fluid is considered to be completely mixed whereas gradients perpendicular to the substratum for an arbitrary number of substances are calculated in the biofilm pore water. Biotic conversion reactions for example, Monod type kinetics are defined by the user, while the equations describing transport processes for example, Fick's law is implemented in AQUASIM. Due to the high flow rates normally applied, TBRs are typically simulated as one completely mixed reactor compartment (Horn \& Hempel, 1997), especially when operated in recycle mode. To consider the axial changes in concentrations characteristic for plug flow at lower flow rates, we modeled the TBR as a series of three interconnected biofilm segments, named S1 to S3 (Figure 2). Thus, the 1D model transforms into a pseudo 2D model. This approach is recommended (Rittmann et al., 2018; Wanner \& Morgenroth, 2004) but has not yet been applied to real data. The specific surface area of each of the three segments was equal to $0.025 \mathrm{~m}^{2}$, reflecting the actual inner

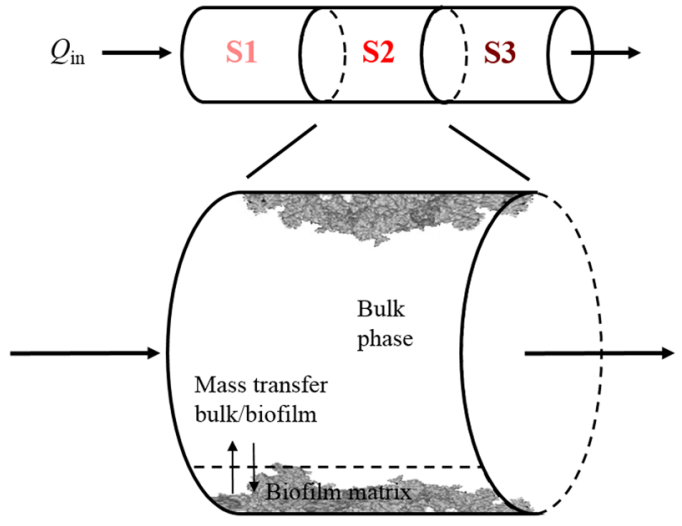

FIGURE 2 Schematic representation of the biofilm reactor in the model. The segments S1, S2, and S3 refer to a length of $133 \mathrm{~mm}$ [Color figure can be viewed at wileyonlinelibrary.com]

surface area of the TBR of $0.075 \mathrm{~m}^{2}$ in total. The actual biofilm surface area is a function of the distance from the substratum. As initial values, all concentrations in the biofilm and bulk liquid were assumed equal to the corresponding influent concentrations as the impact of the very thin initial biofilm layer $(10 \mu \mathrm{m}$, see Table 2$)$ is considered negligible. Mass transfer of substrate, product, and protons into and out of the biofilm, as well as their mass transport within the biofilm matrix, were described by diffusion. As mass transport is considered only in the liquid phase of the biofilm $\left(1-\varepsilon_{\mathrm{x}}=0.86\right.$, Table 2$)$, the corresponding diffusion coefficients in water were used in the model. The kinetic model parameters were calculated by minimizing the sum of the squares of the weighted deviations $\left(\chi^{2}\right)$ among measurements and calculated model results. Table 2 summarizes the important parameters of the simulation.

\section{RESULTS AND DISCUSSION}

\subsection{Preliminary experiment: Batch lactic acid production with planktonic cells}

To analyze lactic acid production with planktonic cells and to determine the growth parameters, batch experiments $(n=2)$ were performed. Growth, substrate consumption and lactic acid production data for one representative experiment as well as the deduced growth parameters are given in Figure 3a,b. Cell growth ceased before substrate depletion, resulting in a low BDW concentration of

TABLE 1 Process matrix for the simulation of lactic acid production

\begin{tabular}{|c|c|c|c|c|c|}
\hline \multirow[b]{2}{*}{ Process } & \multicolumn{4}{|c|}{ Components } & \multirow[b]{2}{*}{ Process rate $r_{i}$} \\
\hline & $\begin{array}{l}\text { Substrate } \\
S\end{array}$ & $\begin{array}{l}\text { Product } \\
P\end{array}$ & $\begin{array}{l}\text { Proton } \\
\mathrm{H}\end{array}$ & $\begin{array}{l}\text { Biomass } \\
X\end{array}$ & \\
\hline Cell growth and growth-associated production & $-\frac{1}{Y_{X S}}$ & $\frac{Y_{P S}}{Y_{X S}}$ & $\frac{Y_{P S}}{Y_{X S}}$ & 1 & $\mu_{\max } \cdot \frac{c_{S}}{K_{S}+c_{S}} \cdot \frac{K_{H}}{K_{H}+c_{H}} \cdot X$ \\
\hline Non growth-associated production & $-\frac{1}{Y_{X S}}$ & 1 & 1 & - & $\beta_{\max } \cdot \frac{c_{S}}{K_{S}+c_{S}} \cdot X$ \\
\hline Biomass detachment & - & - & - & -1 & $k_{\mathrm{D}} \cdot u_{\mathrm{F}}$ \\
\hline
\end{tabular}


TABLE 2 Kinetic parameters for the simulation of lactic acid production

\begin{tabular}{|c|c|c|c|c|}
\hline Parameter & Symbol & Value & Unit & Source \\
\hline \multicolumn{5}{|l|}{ Rates } \\
\hline Maximum growth rate & $\mu_{\max }$ & 0.63 & $1 / \mathrm{h}$ & This study, batch experiment \\
\hline Maximum nongrowth associated production rate & $\beta_{\max }$ & 0.10 & $1 / \mathrm{h}$ & This study, batch experiment \\
\hline \multicolumn{5}{|l|}{ Constants } \\
\hline Monod constant for substrate & $K_{\mathrm{S}}$ & 0.01 & $g / L$ & Yabannavar and Wang (1991) \\
\hline Inhibition constant for proton & $K_{\mathrm{H}}$ & $1.0 \cdot 10^{6}$ & $g / L$ & Fitted \\
\hline \multicolumn{5}{|l|}{ Yield coefficients } \\
\hline Biomass yield & $Y_{\mathrm{XS}}$ & 0.05 & $\mathrm{~g} / \mathrm{g}$ & This study, batch experiment \\
\hline Product yield & YPS & 0.94 & $\mathrm{~g} / \mathrm{g}$ & This study, continuous mode \\
\hline \multicolumn{5}{|l|}{ Diffusion coefficients } \\
\hline Substrate & $D_{\mathrm{S}}$ & 0.835 & $\mathrm{~cm}^{2} / \mathrm{d}$ & Ribeiro et al. (2006) \\
\hline Product & $D_{\mathrm{P}}$ & 1.120 & $\mathrm{~cm}^{2} / \mathrm{d}$ & Ribeiro et al. (2005) \\
\hline Proton & $D_{\mathrm{H}}$ & 8.808 & $\mathrm{~cm}^{2} / \mathrm{d}$ & Calculated \\
\hline Detachment coefficient & $k_{\mathrm{D}}$ & 0.83 & - & Fitted \\
\hline Dry biomass of solid fraction in biofilm volume & $\rho_{\mathrm{X}}$ & 205 & $\mathrm{~kg} / \mathrm{m}^{3}$ & This study, continuous mode \\
\hline Volume fraction of biomass & $\varepsilon_{x}$ & 0.14 & - & This study, continuous mode \\
\hline Initial biofilm thickness & $L_{F, 0}$ & 10 & $\mu \mathrm{m}$ & Fitted \\
\hline \multicolumn{5}{|l|}{ Concentrations in influent } \\
\hline Substrate & $c_{S, \text { in }}$ & 5 & $g / L$ & \\
\hline Proton & $c_{\mathrm{H}, \text { in }}$ & $10^{6}$ & $g / L$ & \\
\hline Flow rate & $v$ & 0.32 & $\mathrm{~mm} / \mathrm{s}$ & \\
\hline
\end{tabular}

only $1.5 \mathrm{~g} / \mathrm{L}$. As the $\mathrm{pH}$ value is controlled in the batch culture, this indicates a possible product inhibition at approx. $30 \mathrm{~g} / \mathrm{L}$ of lactic acid, as has already been observed before (Goncalves, Xavier, Almeida, \& Carrondo, 1991; Kumar Dutta et al., 1996). Lactic acid production continued at a reduced rate even when net growth ceased after $42 \mathrm{hr}$, showing that the production is both growth and nongrowth associated. Despite high specific productivity, the maximum volumetric productivity reached only $1.2 \mathrm{~g} \cdot \mathrm{L}{ }^{1} \cdot \mathrm{hr}^{1}$ due to the low biomass concentration. This is in accordance with recent studies, where volumetric productivities with different bacterial strains and fermentation conditions varied from 0.65 to $3.20 \mathrm{~g} \cdot \mathrm{L}{ }^{1} \cdot \mathrm{hr}{ }^{1}$ (Gao, Wong, Ng, \& Ho, 2012; Liu et al., 2010; Meng, Xue, Yu, Gao, \& Ma, 2012; Velázquez et al., 2001). The low biomass but high product yields $\left(Y_{X S}=0.06 \pm 0.01 \mathrm{~g} / \mathrm{g} ; Y_{P S}=0.87 \pm 0.01 \mathrm{~g} / \mathrm{g}\right)$ are characteristic for anaerobically cultivated microorganisms and represent the desired features for efficient product formation. Our results identify (a)

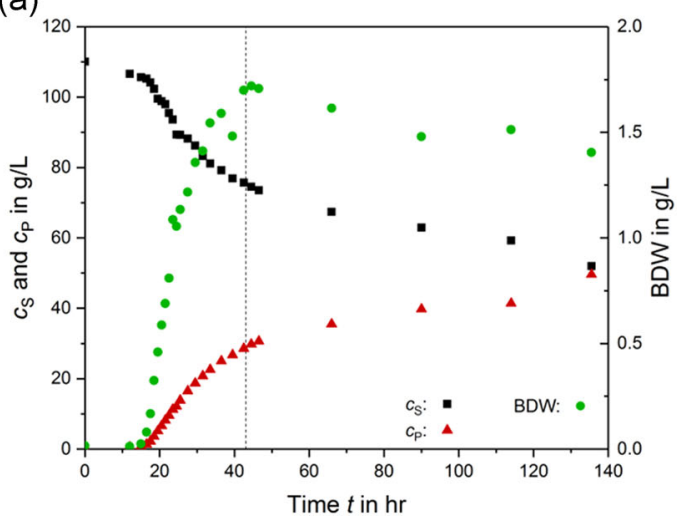

(b)

\begin{tabular}{llll}
\hline Parameter & Symbol & Value & Unit \\
\hline $\begin{array}{l}\text { Maximum growth rate } \\
\begin{array}{l}\text { Maximum non growth-associated } \\
\text { production rate }\end{array}\end{array}$ & $\mu_{\max }$ & $0.34 \pm 0.03$ & $1 / \mathrm{h}$ \\
Maximum BDW concentration & $c(\mathrm{BDW})_{\max }$ & $0.10 \pm 0.03$ & $1 / \mathrm{h}$ \\
$\begin{array}{l}\text { Biomass yield coefficient } \\
\text { Product yield coefficient }\end{array}$ & $Y_{\mathrm{XS}}$ & $0.06 \pm 0.01$ & $\mathrm{~g} / \mathrm{L}$ \\
Maximum productivity & $\mathrm{Y}_{\mathrm{PS}}$ & $0.87 \pm 0.01$ & $\mathrm{~g} / \mathrm{g}$ \\
\hline
\end{tabular}

FIGURE 3 (a) Growth (given as CDW), substrate consumption and lactic acid production data ( $c_{\mathrm{S}}$ and $c_{\mathrm{P}}$ ) for one representative batch culture using planktonic cells. The dotted line separates growth and nongrowth associated lactic acid production. (b) Growth and lactic acid production parameters as deduced from batch experiments $(n=2)$ [Color figure can be viewed at wileyonlinelibrary.com] 
the major known bottlenecks in conventional lactic acid production, namely low biomass concentration and high residual substrate concentration due to product inhibition as well as short fermentation times for growth associated production, and substantiate the need for alternative production processes.

\subsection{Continuous lactic acid production in the TBR}

\subsubsection{Biofilm visualization and analysis}

Biofilm growth started at the bottom of the TBR over its entire length, indicating that gravity promoted initial cell attachment. From there, biofilm grew upwards until after 4 days of cultivation the entire cross sectional area of the TBR was covered (data not shown). At the end of the cultivation period, the TBR was analyzed by MRI (Figures $4 a, b$ ). The drainage during sample preparation led to the detachment of $22 \%$ of the total biofilm biomass as determined by weighing. To consider the lost biomass within the simulation, this amount was uniformly added to the measured values of biofilm thickness $L_{F \text { meas }}$, as deduced from the MR images. These corrected values are subsequently referred to as $L_{F \text { corr. }}$ Consequently, the analysis of MR images revealed a final mean biofilm thickness $L_{F \text { corr }}$ of approx. $1,350 \mu \mathrm{m}$ before drainage. However, $L_{F \text { corr }}$ is subject to large variations over the reactor length. Whereas the mean thickness averages $2,300 \mu \mathrm{m}$ at the beginning of the glass TBR, it only amounts to approximately $850 \mu \mathrm{m}$ in the two thirds downstream. The decrease of $L_{F \text { corr }}$ might reflect a possible growth inhibition that will be discussed below.

The biofilm grown at the inlet of the TBR was visualized by CLSM (Figure 5). Subsequent studies showed that the structure of the biofilm is independent of the position along the TBR (data not shown). Staining of the glycoconjugates revealed only a small amount of extracellular polymeric substances (EPS) consisting mostly of cell wall bound glycopolymers of the glycocalyx (Staudt, Horn, Hempel, \& Neu, 2003). The inner cohesion of the biofilm might be additionally

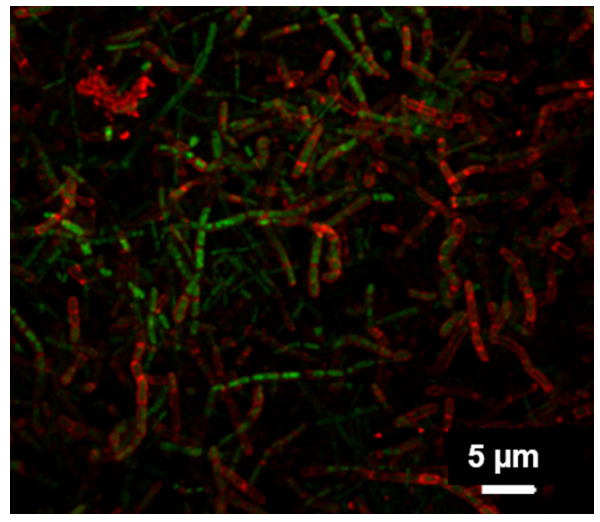

FIGURE 5 Confocal laser scanning microscopy image of 27 days old biofilm. Green: nucleic acid stain (SYTO60); red: glycoconjugates stain (BanLec) [Color figure can be viewed at wileyonlinelibrary.com]

assured through cell cell adhesion by pili. A low EPS production is advantageous in biotechnological production, because the product yield is not significantly reduced as compared with planktonic cultivation.

Analysis of the biofilm by BWW and BDW determination (Section 2.3) revealed a high water content of $96.5 \%$, and a biofilm dry density of $28.5 \mathrm{~g} / \mathrm{L}$, defined as BDW per biofilm volume. Due to the negligible amount of EPS, the high biofilm density is equivalent to a high cell density, which should have a positive effect on the productivity of the process (Dagher et al., 2010; Halan et al., 2012; John et al., 2007).

\subsubsection{Biofilm productivity}

The productivity of the biofilm $Q_{P}$ over the course of the cultivation and the corresponding $\mathrm{pH}$ values measured at the outlet of the TBR are depicted in Figure 6a,b. Values were obtained for three different flow velocities. In each case, lactic acid productivity reached a stable value after a short start up phase and could be maintained for the

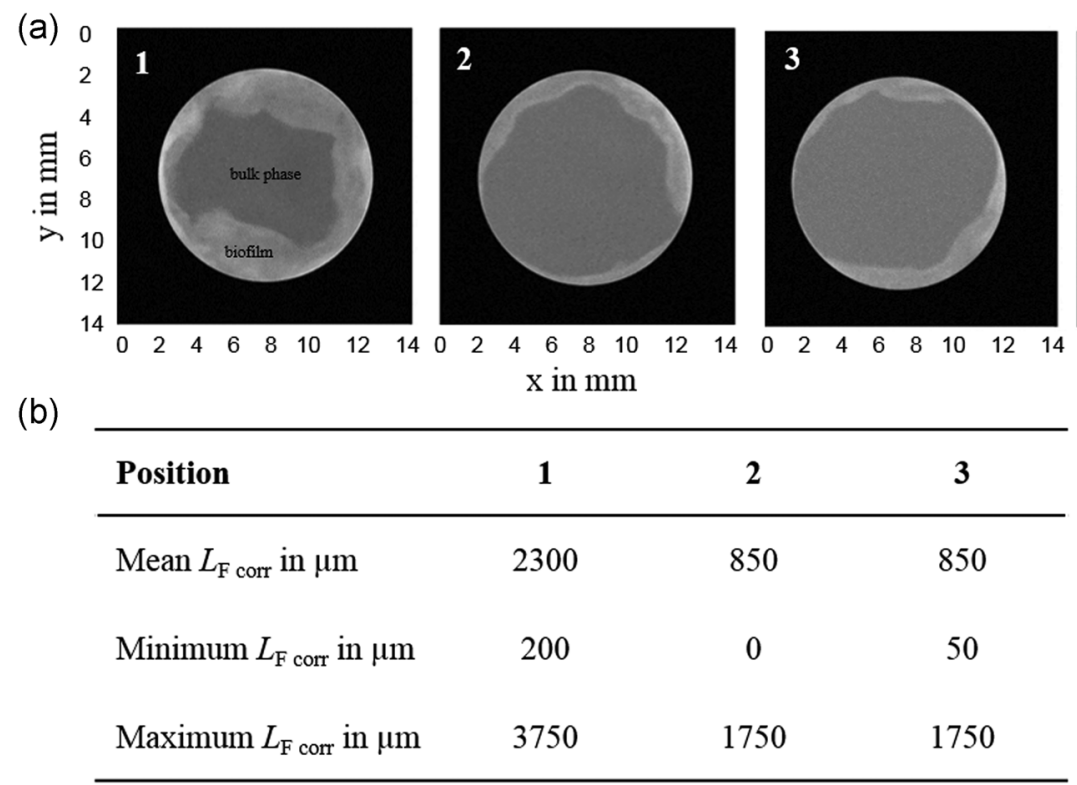

FIGURE 4 (a) Magnetic resonance images of 27 days old biofilm at the beginning (position 1: $70 \mathrm{~mm}$ ), the middle (position 2: $200 \mathrm{~mm}$ ) and the end (position 3: $330 \mathrm{~mm}$ ) of the biofilm reactor. (b) Mean, minimum, and maximum values for the corrected biofilm thickness $L_{F \text { corr }}$ 
(a)

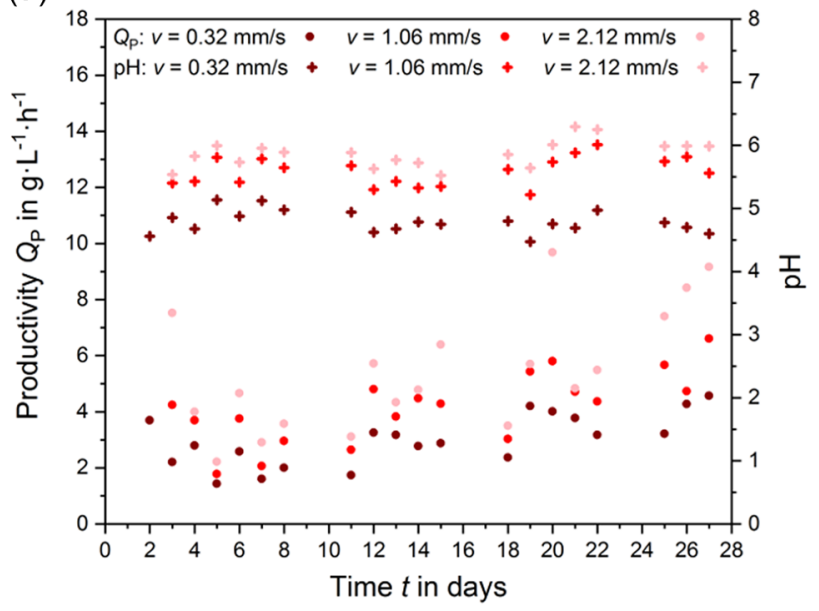

(b)

\begin{tabular}{ll}
\hline Flow velocity $\boldsymbol{v}$ & Mean productivity $\boldsymbol{Q}_{\text {P mean }}$ \\
\hline $0.32 \mathrm{~mm} / \mathrm{s}$ & $3.0 \pm 0.9 \mathrm{~g} \cdot \mathrm{L}^{-1} \cdot \mathrm{h}^{-1}$ \\
$1.06 \mathrm{~mm} / \mathrm{s}$ & $4.1 \pm 1.2 \mathrm{~g} \cdot \mathrm{L}^{-1} \cdot \mathrm{h}^{-1}$ \\
$2.12 \mathrm{~mm} / \mathrm{s}$ & $5.4 \pm 2.1 \mathrm{~g} \cdot \mathrm{L}^{-1} \cdot \mathrm{h}^{-1}$ \\
\hline
\end{tabular}

FIGURE 6 Biofilm productivity $Q_{p}$ and corresponding $\mathrm{pH}$ value in the bulk liquid phase measured at the outlet of the reactor over the course of the cultivation for three different flow velocities $v$. Mean productivities $Q_{P}$ mean for each flow velocity $v$ are indicated [Color figure can be viewed at wileyonlinelibrary.com]

rest of the cultivation period of approx. 3 weeks, proving the suitability of the system for long term cultivation. The variations in $Q_{P}$ over time can be explained by occasional sloughing events of the biofilm, leading to certain variations in biofilm thickness. It was clearly shown that the mean productivity $Q_{\mathrm{P} \text { mean }}$ increased with the flow velocity. As will be later on revealed by the simulation results (Section 4.2.3), the main impact of the flow velocity is the magnitude of $\mathrm{pH}$ change along the reactor length. At the lowest flow velocity $(0.32 \mathrm{~mm} / \mathrm{s})$, the lactic acid production leads to a strong $\mathrm{pH}$ drop to a value of 4.5 at the outlet of the TBR. At the highest velocity $(2.12 \mathrm{~mm} / \mathrm{s})$ in contrast, the $\mathrm{pH}$ can be maintained close to the optimum $\mathrm{pH}$ value of 6.0 throughout all three reactor segments. As additional batch experiments with planktonic cells showed, there is a significant correlation between $\mathrm{pH}$ value and productivity: the lactic acid production rate achieved at a $\mathrm{pH}$ of 6.0 was diminished by $25 \pm 15 \%$ at a pH value of 5 and even by $67 \pm 5 \%$ at a value of 4.5 as compared with the maximum productivity achieved. At a pH of 4.0 , production was completely prevented (data not shown). Furthermore, deviation of the $\mathrm{pH}$ from its optimum value has a negative impact on the growth rate itself and cell growth completely ceases below a pH value of 4 (Stenroos, Linko, \& Linko, 1982). Since lactic acid production leads to a strong $\mathrm{pH}$ gradient along the TBR, $\mathrm{pH}$ inhibition, thus, also explains the decrease in biofilm thickness over the reactor length as observed by MRI (Section 4.2.1)

The maximum productivity, achieved at a flow velocity of $2.12 \mathrm{~mm} / \mathrm{s}$, reached a value of $7-10 \mathrm{~g} \cdot \mathrm{L}{ }^{1} \cdot \mathrm{hr}{ }^{1}$ with a high product yield of $0.94 \pm 0.06 \mathrm{~g} / \mathrm{g}$. In comparison to the batch culture with planktonic cells as used in industrial production, the maximum productivity in the biofilm system could hence be increased by a factor of 6-8. As this productivity increase is ascribed to the high cell density and not to the continuous operation itself, alternative continuous processes without some sort of cell retention are considered uncompetitive, especially since product concentrations have to be kept below the inhibitory level. The production rates for pure cultures, achieved recently in different operational systems using biofilms on carrier material, vary between 4.2 and $8.95 \mathrm{~g} \cdot \mathrm{L}^{1} \cdot \mathrm{hr}{ }^{1}$ (Cotton, Pometto, \& Gvozdenovic Jeremic, 2001; Rangaswamy \& Ramakrishna, 2008; Velázquez et al., 2001). However, a direct comparison of the different processes is hardly possible, as the volumetric productivity varies highly with the reactor design, the surface to volume ratio (SA/V) being a major factor determining reactor efficiency. The flux is typically used as a parameter describing biofilm turnover performance. It is defined as product transport out of the biofilm per biofilm surface area and amounts to $324 \mathrm{~g} \cdot \mathrm{m}^{2} \cdot \mathrm{d}^{1}$ in this experiment. Therefore, adapting the $\mathrm{SA} / \mathrm{V}$ and overcoming the $\mathrm{pH}$ limitation hold potential for further increasing the volumetric productivity in this application.

\subsubsection{Simulation results}

The measured and predicted consumption rates of glucose $Q_{S}$, the production rates of lactic acid $Q_{P}$ and the $\mathrm{pH}$ values in the bulk liquid are depicted over the course of the cultivation in Figure $7 \mathrm{a}$. All data refer to the lowest flow velocity of $0.32 \mathrm{~mm} / \mathrm{s}$. The increase of $Q_{s}$ and $Q_{p}$, and the decrease of the $\mathrm{pH}$ value result from the process of biofilm growth. To avoid the complexity of the model, the occasional, inevitable sloughing events are not taken into account, and the variations in $Q_{s}$ and $Q_{p}$ are, thus, approximated by a steady increase. Apart from the start up phase of approx. 2 days, the simulation can satisfactorily represent the general trend of the data. Figure $7 \mathrm{~b}$ shows the comparison between measured (given as $L_{F}$ corr) and predicted data for the biofilm thickness $L_{F}$. As experimental data are only available at the end of the experiment, the development of biofilm thickness over time is not verified. However, as the modeled substrate and product concentrations (Figure 7a) depend on the biomass present, the model is coherent in itself. The model predicts the decreasing thickness over the reactor length due to the increasing 

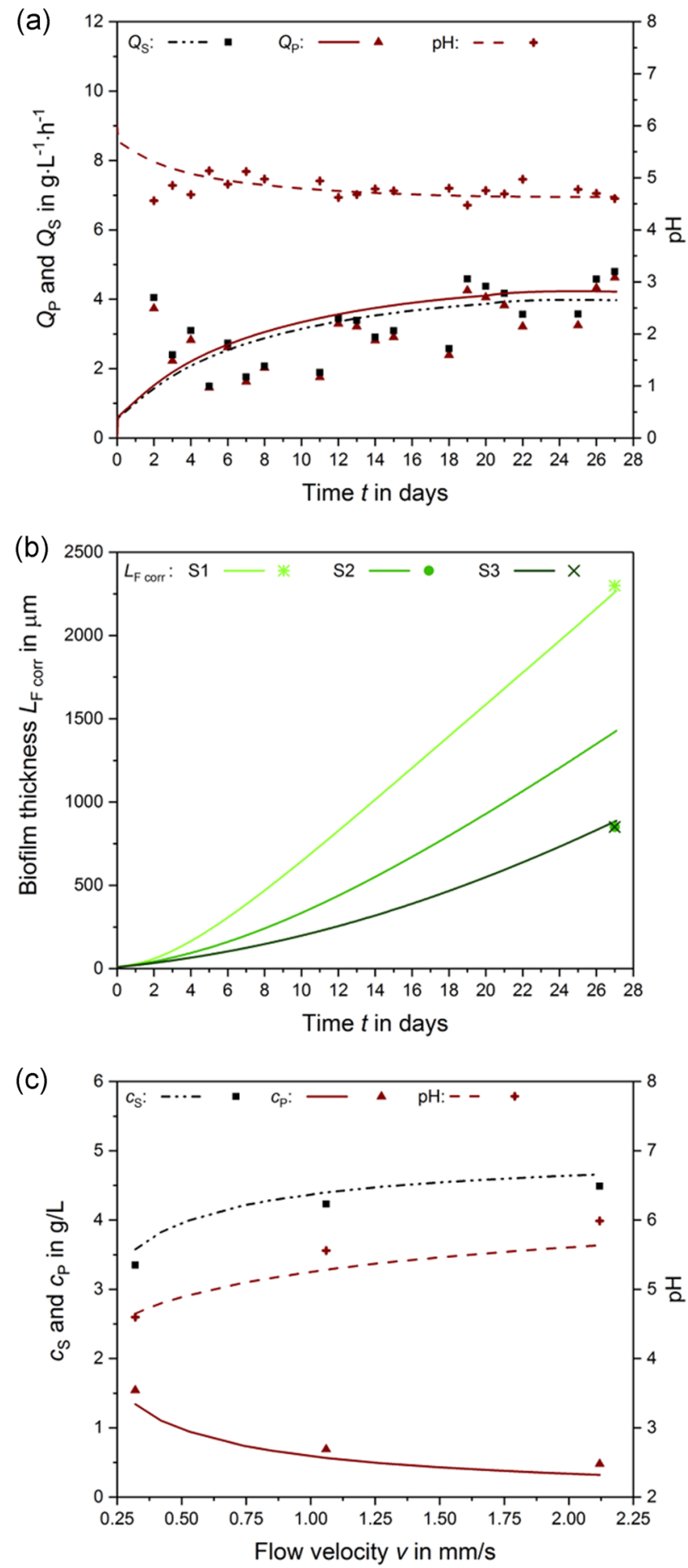

FIGURE 7 Comparison of experimentally determined and predicted parameters in the bulk liquid phase over the course of cultivation $(v=0.32 \mathrm{~mm} / \mathrm{s})$ : (a) Glucose consumption and lactic acid production rates $Q_{S}$ and $Q_{P}$, as well as $p H$ value. (b) Biofilm thickness $L_{F}$ corr in the three interconnected segments S1 to S3. (c) Substrate and lactic acid concentrations $\left(c_{S}\right.$ and $\left.c_{\mathrm{P}}\right)$ and $\mathrm{pH}$ value as a function of flow velocity at Day 27 [Color figure can be viewed at wileyonlinelibrary.com]

$\mathrm{pH}$ inhibition. However, as sloughing is not considered, the model assumes a constant decrease, and therefore overestimates $L_{F}$ in the second segment of the TBR, which was determined to be similar to the one of the third segment (cf. Figure 4). Figure 7c shows the influence of the flow velocity on the concentrations $c_{S}$ and $c_{\mathrm{P}}$, and the resulting $\mathrm{pH}$ values obtained in a short term experiment on Day 27. The figure confirms the previous statement (Figure 6) that the major impact of the flow velocity is the magnitude of $\mathrm{pH}$ change along the reactor length: The smaller the flow velocity, the higher the lactic acid concentration and, thus, $\mathrm{pH}$ drop and the more significant the $\mathrm{pH}$ inhibition. The experimental values can be satisfactorily represented by the model, which further confirms its validity.

After comparison against the experimental data, the model was used to predict data that are difficult to obtain experimentally. The changes of $Q_{s}$ and $Q_{p}$, which could only be determined as integral values at the outlet of the TBR, were calculated over the reactor length and are depicted in Figure 8a. It can be seen that in each segment of the TBR, the substrate consumption rate is only slightly inferior to the production rate, as a result of the aforementioned high product yield. In the first segment, $Q_{P}$ increases with the cultivation time due to the growth of biofilm, and thus increase of biomass. However, the increase decelerates after approx. 4 days of cultivation and from Day 23 on, $Q_{P}$ even starts dropping. It seems that when a certain biofilm thickness is reached, mass transport limitations of lactic acid out of the biofilm lead to $\mathrm{pH}$ inh bition within the film, which causes the productivity increase to slow down. The simulation clearly shows that already from Day 23 on, additional mass transport limitations of glucose occur, resulting in a substrate depletion towards the substratum (data not shown, cf. $c_{S}$ in Figure $8 \mathrm{~b}$ ). The amount of productive biomass is, thus, reduced, causing the observed productivity decline. In the second and third segment, $Q_{P}$ follows cell growth, indicating that in the thinner biofilm, mass transport limiting conditions are minor.

Substrate and product concentrations $c_{S}$ and $c_{\mathrm{P}}$, and $\mathrm{pH}$ values inside the biofilm at the end of the cultivation period (Day 27) are shown for S1 (Figure 8b) and S3 (Figure 8c) at the lowest and the highest flow velocity $(0.32$ and $2.12 \mathrm{~mm} / \mathrm{s})$. In the first segment of the TBR, the biofilm thickness of 2,300 $\mu \mathrm{m}$ leads to limiting conditions close to the substratum for both flow velocities. Whereas substrate is depleted at a biofilm depth of approx. 1,800 $\mu$ m (within the first $500 \mu \mathrm{m}$ biofilm above the substratum), the $\mathrm{pH}$ decreases to a value of 4.0 already at a depth of approx. 1,000 $\mu \mathrm{m}(1,300 \mu \mathrm{m}$ above the substratum). As lactic acid production is prevented at $\mathrm{pH}<4.0$, almost two thirds of the biofilm volume in this segment do not contribute to production, leading to reduced specific productivity as compared with planktonic cells. In segment $\mathrm{S} 3$, with a mean biofilm thickness of $850 \mu \mathrm{m}$, glucose concentration is not limiting the turnover processes and the $\mathrm{pH}$ drop is limited to values $>4.0$ throughout the whole biofilm depth. However, the lactic acid concentration at the substratum of $2.2-2.5 \mathrm{~g} / \mathrm{L}$ creates $\mathrm{pH}$ values between 4.2 and 4.4 , a range where $\mathrm{pH}$ inhibition already occurs and lactic acid production is significantly decelerated. Production is thus strongly inhibited by mass transport limitations, where the insufficient product removal is by far more significant than the substrate supply. Increasing the flow velocity from 0.32 to $2.12 \mathrm{~mm} / \mathrm{s}$ results in a minor $\mathrm{pH}$ drop in the bulk phase and increases the mass transfer of product out of the biofilm. This has an impact on the lactic acid 

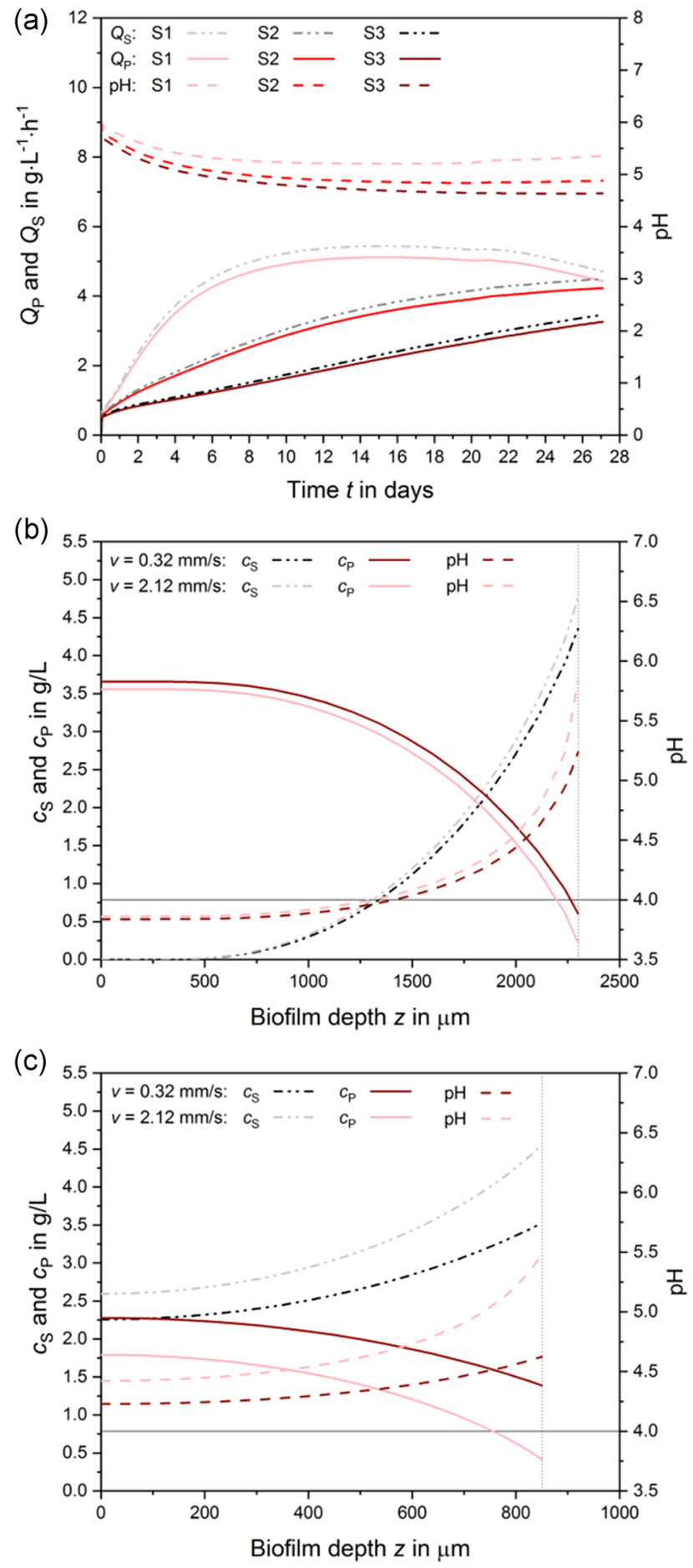

FIGURE 8 (a) Predicted values of $Q_{s}, Q_{p}$, and $\mathrm{pH}$ over the course of the cultivation along the reactor length (segments $\mathrm{S} 1$ to $\mathrm{S} 3$ ). Comparison of $c_{\mathrm{S}}, c_{\mathrm{P}}$, and $\mathrm{pH}$ inside the biofilm at Day 27 for a flow velocity of 0.32 and $2.12 \mathrm{~mm} / \mathrm{s}$ in segment S1 (b) and S3 (c). Dotted lines represent the biofilm thickness $L_{F}$ corr in $S 1$ and $S 3$ as measured by magnetic resonance imaging. The $\mathrm{pH}$ value of 4.0 is highlighted by a straight line [Color figure can be viewed at wileyonlinelibrary.com]

concentrations and the $\mathrm{pH}$ values inside the biofilm, especially at low depths. The importance of this effect increases axially along the reactor length so that the influence of the velocity is further pronounced towards the outlet of the TBR. Consequently, the magnitude of the encountered limitations is decreased, which confirms the previous statement that the productivity increase is due to an improved mass transport. To prevent a significant productivity decline, biofilm thickness should therefore be limited to $500 \mu \mathrm{m}$ in the present system. The simulation shows the importance of considering the axial gradients in a plug flow reactor. The gradual increase of product concentration and, thus, growth inhibition has a significant impact on biofilm thickness and biofilm productivity over the reactor length, which cannot be represented by a model assuming a completely mixed reactor as is still the current state of the art (Horn et al., 2003; Rittmann et al., 2018).

Figure 8 illustrates that the inhibition of lactic acid productivity is mainly due to excessive biofilm thickness and the resulting mass transport limitations, causing substrate depletion and product accumulation and hence $\mathrm{pH}$ drop. Biofilm thickness, however, can be controlled, for example, by modifying the flow velocity: Since higher shear forces result in biofilm erosion, an "optimum" biofilm thickness can be adjusted (Costerton, Lewandowski, Caldwell, Korber, \& Lappin Scott, 1995). In this regard, the uniform flow conditions in a TBR are advantageous as compared with other cultivation processes (e.g. fixed bed reactor). The study thus confirms the control of biofilm thickness as a key factor in productive biofilm processes. An additional $\mathrm{pH}$ regulation over the reactor length could also contribute to a significant increase of the achieved turnover rates.

\section{CONCLUSIONS}

Our results lead to the following conclusions:

(i) A strain of L. delbrueckii, although initially selected for high lactic acid production in planktonic state, can be cultivated in a biofilm. Biofilm formation and cultivation was achieved without preliminary immobilization steps in a glass TBR, a very simple system and allowing good insight.

(ii) The cell density in the biofilm system was increased by a factor of 19 as compared with the planktonic culture. This resulted in an increased volumetric productivity by a factor of 6-8 when working at the very low substrate and product concentrations. Control of biofilm thickness to overcome the $\mathrm{pH}$ inhibition resulting from lactic acid production and optimization of the dimensions (e.g. increasing the specific surface area) and design of the cultivation system present a high potential for further productivity increase.

(iii) Lactic acid production reached $80 \%$ of the maximum value after 10 days and could be maintained for a period of more than 2 weeks, proving the suitability of the biofilm system for long term cultivation.

(iv) A simple model for cell growth and lactic acid production within a biofilm was developed for the first time, which deepens the understanding of the biofilm system and can facilitate future optimization. 


\section{ACKNOWLEDGMENTS}

The authors thank the German Technical and Scientific Association for Gas and Water (DVGW) and the "Freundeskreis des Engler Bunte Instituts" for funding. Ute Kuhlicke and Dr. Thomas Neu (Helmholtz Centre for Environmental Research, Magdeburg, Germany) are gratefully acknowledged for the CLSM image. We also thank BASF SE for the provision of the microorganism L. delbrueckii. DFG is acknowledged for financial support within the instrumental facility Pro $^{2}$ NMR.

\section{REFERENCES}

Al-Kaidy, H., Duwe, A., Huster, M., Muffler, K., Schlegel, C., Sieker, T., ... Ulber, R. (2015). Biotechnology and bioprocess engineering From the first Ullmann's article to recent trends. ChemBioEng Reviews, 2(3), 175 184. https://doi.org/10.1002/cben.201500008

Brading, M. G., Jass, J., \& Lappin-Scott, H. M. (1995). Dynamics of bacterial biofilm formation. In H. M. Lappin-Scott, \& J. W. Costerton (Eds.), Microbial Biofilms (pp. 46 63). Cambridge: Cambridge University Press.

Brink, H. G., \& Nicol, W. (2014). The influence of shear on the metabolite yield of Lactobacillus rhamnosus biofilms. New Biotechnology, 31(5), 460467.

Callaghan, P. T. (1993). Principles of nuclear magnetic resonance microscopy. Clarendon Press.

Characklis, W. G., \& Marshall, K. C. (1990). Biofilms. Wiley.

Costerton, J. W., Lewandowski, Z., Caldwell, D. E., Korber, D. R., \& Lappin-Scott, H. M. (1995). Microbial biofilms. Annual Reviews in Microbiology, 49(1), 711745.

Cotton, J., Pometto, A., \& Gvozdenovic-Jeremic, J. (2001). Continuous lactic acid fermentation using a plastic composite support biofilm reactor. Applied Microbiology and Biotechnology, 57(5-6), 626630. https://doi.org/10.1007/s002530100820

Dagher, S. F., Ragout, A. L., Siñeriz, F., \& Bruno-Bárcena, J. M. (2010). Cell immobilization for production of lactic acid: Biofilms do it naturally. Advances in Applied Microbiology, 71, 113148.

De Man, J. C., Rogosa, M., \& Sharpe, M. E. (1960). A medium for the cultivation of lactobacilli. Journal of Applied Bacteriology, 23(1), 130 135. https://doi.org/10.1111/j.1365-2672.1960.tb00188.x

Demirci, A., \& Pometto, A. L., III (1995). Repeated-batch fermentation in biofilm reactors with plastic-composite supports for lactic acid production. Applied Microbiology and Biotechnology, 43(4), 585589. https://doi.org/10.1007/BF00164758

Fan, R., Ebrahimi, M., Quitmann, H., \& Czermak, P. (2015). Lactic acid production in a membrane bioreactor system with thermophilic Bacillus coagulans:Fouling analysis of the used ceramic membranes. Separation Science and Technology, 50(14), 2177 2189. https://doi.org/ 10.1080/01496395.2015.1031401.

Gao, T., Wong, Y., Ng, C., \& Ho, K. (2012). L-lactic acid production by Bacillus subtilis MUR1. Bioresource Technology, 121, 105 110. https:// doi.org/10.1016/j.biortech.2012.06.108

Goncalves, L., Xavier, A., Almeida, J., \& Carrondo, M. (1991). Concomitant substrate and product inhibition kinetics in lactic acid production. Enzyme and Microbial Technology, 13(4), 314319.

Gross, R., Hauer, B., Otto, K., \& Schmid, A. (2007). Microbial biofilms: New catalysts for maximizing productivity of long-term biotransformations. Biotechnology and Bioengineering, 98(6), 11231134.
Gross, R., Schmid, A., \& Buehler, K. (2012). Catalytic biofilms: A powerful concept for future bioprocesses. In G. Lear, \& G. D. Lewis (Eds.), Microbial biofilm: Current research and applications (pp. 193 222). Norfolk, UK: Caister Academic Press.

Halan, B., Buehler, K., \& Schmid, A. (2012). Biofilms as living catalysts in continuous chemical syntheses. Trends in Biotechnology, 30(9), 453465.

Herrling, M. P., Guthausen, G., Wagner, M., Lackner, S., \& Horn, H. (2015). Determining the flow regime in a biofilm carrier by means of magnetic resonance imaging. Biotechnology and Bioengineering, 112(5), 1023 1032. https://doi.org/10.1002/bit.25510

Ho, K., Pometto, A. L., \& Hinz, P. N. (1997). Optimization of L-(+)-lactic acid production by ring and disc plastic composite supports through repeated-batch biofilm fermentation. Applied and Environmental Microbiology, 63(7), 25332542.

Horn, H., \& Hempel, D. C. (1997). Growth and decay in an auto-/ heterotrophic biofilm. Water Research, 31(9), 2243 2252. https://doi. org/10.1016/S0043-1354(97)00081-X

Horn, H., Reiff, H., \& Morgenroth, E. (2003). Simulation of growth and detachment in biofilm systems under defined hydrodynamic conditions. Biotechnology and Bioengineering, 81(5), 607 617. https://doi. org/10.1002/bit.10503

John, R. P., Nampoothiri, K. M., \& Pandey, A. (2007). Polyurethane foam as an inert carrier for the production of $\mathrm{L}(+)$-lactic acid by Lactobacillus casei under solid-state fermentation. Letters in Applied Microbiology, 44(6), 582 587. https://doi.org/10.1111/j.1472-765X. 2007.02137.x

Karel, S. F., Libicki, S. B., \& Robertson, C. R. (1985). The immobilization of whole cells: Engineering principles. Chemical Engineering Science, 40(8), 1321 1354. https://doi.org/10.1016/0009-2509(85)80074-9

Kim, D. H., Lee, M. K., Hwang, Y., Im, W. T., Yun, Y. M., Park, C., \& Kim, M. S. (2016). Microbial granulation for lactic acid production. Biotechnology and Bioengineering, 113(1), 101 111. https://doi.org/10.1002/bit.25540

Kimmich, R. (1997). NMR: Tomography, diffusometry, relaxometry. Berlin, Heidelberg: Springer.

Kumar Dutta, S., Mukherjee, A., \& Chakraborty, P. (1996). Effect of product inhibition on lactic acid fermentation: Simulation and modelling. Applied Microbiology and Biotechnology, 46(4), 410413. https://doi.org/10.1007/bf00166238

Kwon, S., Yoo, I.-K., Lee, W. G., Chang, H. N., \& Chang, Y. K. (2001). Highrate continuous production of lactic acid by Lactobacillus rhamnosus in a two-stage membrane cell-recycle bioreactor. Biotechnology and Bioengineering, 73(1), 2534.

Li, X. Z., Webb, J. S., Kjelleberg, S., \& Rosche, B. (2006). Enhanced benzaldehyde tolerance in Zymomonas mobilis biofilms and the potential of biofilm applications in fine-chemical production. Applied and Environmental Microbiology, 72(2), 1639 1644. https://doi.org/10. 1128/aem.72.2.1639-1644.2006

Liu, B., Maohua, Y., Qi, B., Chen, X., Su, Z., \& Yinhua, W. (2010). Optimizing L-(+)-lactic acid production by thermophile Lactobacillus plantarum As.1.3 using alternative nitrogen sources with response surface method. Biochemical Engineering Journal, 52(2/3), 212219.

Luedeking, R., \& Piret, E. L. (1959). A kinetic study of the lactic acid fermentation. Batch process at controlled $\mathrm{pH}$. Journal of Biochemical and Microbiological Technology and Engineering, 1(4), 393 412. https:// doi.org/10.1002/jbmte.390010406

Meng, Y., Xue, Y., Yu, B., Gao, C., \& Ma, Y. (2012). Efficient production of Llactic acid with high optical purity by alkaliphilic Bacillus sp. WL-S2O. Bioresource Technology, 116, 334 339. https://doi.org/10.1016/j. biortech.2012.03.103

Monod, J. (1949). The growth of bacterial cultures. Annual Review of Microbiology, 3, 371 394. https://doi.org/10.1146/annurev.mi.03. 100149.002103

Muffler, K., \& Ulber, R. (2014). Productive biofilms. Berlin: Springer International Publishing. 
Neu, T. R., \& Lawrence, J. R. (2014). Investigation of microbial biofilm structure by laser scanning microscopy. Advances in Biochemical Engineering/ Biotechnology, 146, 1 51. https://doi.org/10.1007/10 2014272

Neu, T. R., Manz, B., Volke, F., Dynes, J. J., Hitchcock, A. P., \& Lawrence, J. R. (2010). Advanced imaging techniques for assessment of structure, composition and function in biofilm systems. FEMS Microbiology Ecology, 72(1), 1 21. https://doi.org/10.1111/j.1574-6941.2010.00837.x

Posten, C. (2018). Integrated bioprocess engineering. Walter der Gruyter $\mathrm{GmbH}$.

Rangaswamy, V., \& Ramakrishna, S. (2008). Lactic acid production by Lactobacillus delbrueckii in a dual reactor system using packed bed biofilm reactor. Letters in Applied Microbiology, 46(6), 661666.

Reichert, P. (1994). AQUASIM A tool for simulation and data analysis of aquatic systems. Water Science and Technology, 30(2), 2130. https://doi.org/10.2166/wst.1994.0025

Ren, J. (2010). Biodegradable poly(lactic acid): Synthesis, modification, processing and applications. Beijing; Heidelberg: Tsinghua University Press; Springer.

Ribeiro, A. C. F., Lobo, V. M. M., Leaist, D. G., Natividade, J. J. S. Veríssimo, L. P., Barros, M. C. F., \& Cabral, A. M. T. D. P. V. (2005). Binary diffusion coefficients for aqueous solutions of lactic acid. Journal of Solution Chemistry, 34(9), 1009 1016. https://doi.org/10. 1007/s10953-005-6987-3

Ribeiro, A. C. F., Ortona, O., Simões, S. M. N., Santos, C. I. A. V., Prazeres, P. M. R. A., Valente, A. J. M., \& Burrows, H. D. (2006). Binary mutual diffusion coefficients of aqueous solutions of sucrose, lactose, glucose, and fructose in the temperature range from (298.15 to 328.15) K. Journal of Chemical \& Engineering Data, 51(5), 18361840. https://doi.org/10.1021/je0602061

Rittmann, B. E., Boltz, J. P., Brockmann, D., Daigger, G. T., Morgenroth, E., Sørensen, K. H., \& Vanrolleghem, P. A. (2018). A framework for good biofilm reactor modeling practice (GBRMP). Water Science and Technology, 77(5), 1149 1164. https://doi.org/10.2166/ wst.2018.021

Rosche, B., Li, X. Z., Hauer, B., Schmid, A., \& Buehler, K. (2009). Microbial biofilms: A concept for industrial catalysis? Trends in Biotechnology, 27(11), 636643.

Sahm, H., Antranikian, G., Stahmann, K. P., \& Takors, R. (2014). Industrielle mikrobiologie. Berlin, Heidelberg: Springer.

Santek, B., Ivancić, M., Horvat, P., Novak, S., \& Marić, V. (2006). Horizontal tubular bioreactors in biotechnology. Chemical and Biochemical Engineering Quarterly, 20(4.

Skoneczny, S., \& Tabiś, B. (2015). The method for steady states determination in tubular biofilm reactors. Chemical Engineering Science, 137, 178 187. https://doi.org/10.1016/j.ces.2015.06.024

Staudt, C., Horn, H., Hempel, D. C., \& Neu, T. R. (2003). Screening of lectins for staining lectin-specific glycoconjugates in the EPS of biofilms. In P. Lens, A. P. Moran, T. Mahony, \& P. Stoodley (Eds.), Biofilms in medicine, industry and environmental biotechnology (pp. 308 326). London, United Kingdom: IWA Publishing.

Stenroos, S.-L., Linko, Y.-Y., \& Linko, P. (1982). Production of L-lactic acid with immobilized Lactobacillus delbrueckii. Biotechnology Letters, 4(3), 159 164. https://doi.org/10.1007/BF00144317

Storhas, W. (2013). Bioverfahrensentwicklung. Wiley-VCH.

Tsoligkas, A. N., Winn, M., Bowen, J., Overton, T. W., Simmons, M. J. H., \& Goss, R. J. M. (2011). Engineering biofilms for biocatalysis. ChemBioChem, 12(9), 13911395

Velázquez, A., Pometto lii, A. L., Ho, K.-L. G., \& Demirci, A. (2001). Evaluation of plastic-composite supports in repeated fed-batch biofilm lactic acid fermentation by Lactobacillus casei. Applied Microbiology and Biotechnology, 55(4), 434441.

Wagner, M., Manz, B., Volke, F., Neu, T. R., \& Horn, H. (2010). Online assessment of biofilm development, sloughing and forced detachment in tube reactor by means of magnetic resonance microscopy. Biotechnology and Bioengineering, 107(1), 172 181. https://doi.org/10.1002/bit.22784

Wanner, O., \& Morgenroth, E. (2004). Biofilm modeling with AQUASIM. Water Science and Technology, 49(11-12), 137144.

Wanner, O., \& Reichert, P. (1996). Mathematical modeling of mixed-culture biofilms. Biotechnology and Bioengineering, 49(2), 172 184. https://doi.org/ 10.1002/(SICI)1097-0290(19960120)49:2<172::AID-BIT6>3.0.CO;2-N

Yabannavar, V. M., \& Wang, D. I. (1991). Analysis of mass transfer for immobilized cells in an extractive lactic acid fermentation. Biotechnology and Bioengineering, 37(6), 544 550. https://doi.org/10.1002/bit. 260370608

Yeh, P. L.-H., Bajpai, R. K., \& lannotti, E. L. (1991). An improved kinetic model for lactic acid fermentation. Journal of Fermentation and Bioengineering, 71(1), 75 77. https://doi.org/10.1016/0922-338X(91)90309-5 


\section{Repository KITopen}

Dies ist ein Postprint/begutachtetes Manuskript.

Empfohlene Zitierung:

Cuny, L.; Pfaff, D.; Luther, J.; Ranzinger, F.; Ödman, P.; Gescher, J.; Guthausen, G.; Horn, H.; Hille-Reichel, A.

Evaluation of productive biofilms for continuous lactic acid production. 2019. Biotechnology \& bioengineering, 116.

doi: $\underline{10.5445 / / R / 1000099817}$

Zitierung der Originalveröffentlichung:

Cuny, L.; Pfaff, D.; Luther, J.; Ranzinger, F.; Ödman, P.; Gescher, J.; Guthausen, G.; Horn, H.; Hille-Reichel, A.

Evaluation of productive biofilms for continuous lactic acid production. 2019. Biotechnology \& bioengineering, 116 (10), 2687-2697.

doi: $\underline{10.1002 / b i t .27080}$ 